\title{
EFFECT OF HIV INFECTION ON MORTALITY IN PATIENTS WITH TUBERCULOSIS IN ASIA: A META ANALYSIS
}

\author{
Liza Laela Abida'), Bhisma Murti'), Hanung Prasetya ${ }^{2)}$ \\ ${ }^{1)}$ Masters Program in Public Health, Universitas Sebelas Maret \\ 2)Study Program of Acupunture, Health Polytechnics, Ministry of Health, Surakarta
}

\begin{abstract}
Background: TB/HIV coinfectioned remains the leading cause of mortality among people living with HIV (PLHIV). The purpose of this study was to explore the effect of HIV infection on mortality in patients with tuberculosis in Asia.

Subjects and Method: This was meta-analysis and systematic review. The study was conducted by collecting published studies from Google Scholar, PubMed, Springer Link, Hindawi, Clinical Key, and ProQuest databases, from 2010 to 2020. Keywords used "HIV" AND "mortality" OR "HIV Mortality" OR "Tuberculosis Mortality" AND "cross sectional" AND "adjusted odd ratio". The inclusion criteria were full text, using English or Indonesian language, using cross-sectional study design, and reporting adjusted odds ratio. The articles were selected by PRISMA flow chart. The quantitative data were analyzed using random effect model run on Review Manager 5.3.

Results: 5 studies in Asia (Thailand, China, Malaysia, and Oman) were included for this study. Meta analysis study reported that HIV elevated the risk of mortality in patients with tuberculosis $(\mathrm{aOR}=3.45 ; 95 \% \mathrm{CI}=1.14$ to $10.45 ; \mathrm{p}=0.030)$.
\end{abstract}

Conclusion: HIV elevates the risk of mortality in patients with tuberculosis.

Keywords: HIV, mortality, Tuberculosis

\section{Correspondence:}

Liza Laela Abida. Masters Program in Public Health, Universitas Sebelas Maret. Jl. Ir. Sutami 36A, Surakarta 57126, Central Java. Email: lizalaela@gmail.com. Mobile: 085640115633 . 